\title{
Relative Significance of Barriers to Electric Vehicle Adoption in India using AHP- Fuzzy TOPSIS approach
}

\author{
Pranav P. Kumar ${ }^{1}$, Pranav Narang ${ }^{2}$, Tanushka Singh ${ }^{3}$, Dr. Saurabh Agrawal ${ }^{4}$ \\ \{ kumarpranav0981@gmail.com ${ }^{1}$, pranavnarang1997@gmail.com ${ }^{2}$, tanushkasingh98@ gmail.com ${ }^{3}$, \\ agrawals.iit@gmail.com $\left.{ }^{4}\right\}$ \\ Department of Mechanical Engineering, Delhi Technological University, Delhi, India ${ }^{1,2,3,4}$
}

\begin{abstract}
With India being one of the most populous countries in the world. Road Transportation is a significant mode of commutation, and the majority of the market is dominated by gasoline and diesel vehicles. Growing concern for the environment makes it necessary to switch to a much safer mode of transportation, i.e., Electric Vehicles. However, Electric Vehicles do not occupy a consistent share in the Indian Market. This paper tries to identify barriers to EV adoption and their relative significance so that appropriate focus can be given in the future to those barriers which can facilitate the further inclusion of Electric vehicles in the Indian market.
\end{abstract}

Keywords: Barriers, Electric Vehicle, AHP, Fuzzy-TOPSIS;

\section{Introduction}

Growing environmental concerns and the government's push to the sector, post the Paris Agreement [1], has increased interest in electric vehicles and the factors influencing its sales. Electric Vehicle is currently envisioned to be the problem solver to many ecological problems. The main environmental concern arising from conventional IC engine vehicles is the Green House Gas emissions (GHG [2-3]. In 2015, EVs accounted for just $0.1 \%$ of the global automobile market, with sales of more than 1 million vehicles. Norway and the Netherlands lead with market penetrations of $23 \%$ and $10 \%$, respectively, dominating the global market [4]. The Indian government has announced plans to go "all-electric" by 2030 and is offering various incentives to buyers under the FAME scheme [5].In this paper, we have developed a framework to determine the relative significance of the barriers to EV adoption, specifically to the Indian Market, which needs significant investments-both capital and technology. 


\section{Literature Review}

First, electric vehicles are a new technology and occupy a negligible portion of the Indian auto sector. Therefore, not much sales data is available. Second, EVs require the consumers to shift from fuel at a gasoline station to plug in the vehicles for charging. Third and one of the vital factors right now is the lack of EV charging technology in India and the non-existent electricity supply in a vast portion of rural India. Fourth, EVs cost more than a combustion vehicle, but the recharging costs are lower than fuel costs. Fifth, EVs are not very convenient for long-distance travel as the car will require repeated charging of the batteries, and so the driving pattern of the consumer will also play a decisive role in the EV adoption process. A detailed survey was conducted by the University of Vermont [6]. Their aim was to collect data to (i) find the characteristic differentiating between consumers who are willing and non-willing to adopt EV technology (ii) finding all possible factors influencing a consumer's willingness to consider taking up the new PHEV technology in a positive manner, (iii) gain an insight on the extra amount of money that consumers would consider paying initially to buy a vehicle can help save a fortune of money on fuel costs in the future, Leabeau et al. [7] surveyed in Belgium to determine the awareness of electric vehicles amongst the residents. The ability to charge the car at home perceived as the most crucial factor for the residents. $80 \%$ of the residents didn't have any problem with the maximum speed of the vehicle. Many Residents felt that the government should invest in easy access to charging stations and standardization of the whole system. A study by Zeinab Rezwani, Johan Jansson and Jan Bodin [3] has identified five broad categories of theoretical frameworks which determine the adoption of EV technology, (i) choice theory (ii) Environmental impact (iii) Identity of a consumer and his lifestyle, (iv) Eagerness of a consumer to adopt a technology and how well a technology inculcates future innovations (v) Emotions of a consumer which affects his choices.

\subsection{Criterion for selection of Barriers}

2.1.1. Environmental Impact: The environmental benefits of using electric vehicles is a critical driver in their sales [8]. To gauge the ecological impact, two essential factors considered are Air Pollution (AP) and Green House Gas emissions (GHG) [2]. Battery Electric Vehicles (BEVs) do not produce any direct emissions, which further helps in reducing pollution, but in most cases, the electricity to charge the batteries are from a non-renewable, polluting source [9]. In India, $62.8 \%$ of the total electricity is generated from thermal sources [10]. Renewable sources are required from which electricity can be supplied to produce negligible emissions. Environmental challenges also surround the Lithium-Ion batteries used in electric vehicles. Lithium extraction harms the soil, contributes to air pollution, and recycling of these batteries is difficult [11]

2.1.2. Economic Impact: To encourage more adoption of cleaner fuelled vehicles, governments across the world are providing both technology-specific incentives like subsidies and general policies like reduced tax and loan rates on low emission vehicles (Ex: CNG vehicles, electric vehicles) [12]. In accordance with the commitments made at the Paris Accord, India is trying to reduce its greenhouse gas emissions and thus promoting electric vehicles [13]. In the Budget FY 2019-20, the Indian government launched the FAME -II scheme, setting aside Rs. 10,000 crores for it. Additionally, excise duty has been reduced to $5 \%$, EV purchasing users would be exempted from tax of Rs 2.5 Lakhs, and GST rates for 
EVs are being reduced from $12 \%$ to $5 \%$ [14-15].

2.1.3. Technology: As further innovations are made, they will further give rise to newer, better technologies which can over a period of time be incorporated into Electric Vehicles, improving the consumer experience. Currently, a need for technological improvements in driving range, recharge time, and engine power is felt [16].

2.1.4. Social Impact: Adoption of electric vehicles can potentially spark a cultural shift to using cleaner technologies [17] and hence help reduce environmental damage. The reduced emissions and efficient energy utilization will pave the way to better public health [18]. The socialized health costs of a Honda Civic (in the USA) with a 10-year life cycle is estimated to be $\$ 1686$, and the socialized environmental costs $\$ 866$ [19]. Another benefit of electric vehicles over conventional IC engine vehicles is their "silent" engine and the reduction in noise pollution [20].

2.1.5. Stakeholder's needs: The direct stakeholders of electric vehicles are the potential buyers, car manufacturers, and charging station owners. The indirect stakeholders are the general public, government, and the petroleum industry [20-21]. The needs of the stakeholders vary from each other and often contradict each other. Potential buyers, car manufacturers, charging station owners, the government and the general public are all likely to benefit from increased adoption of electric vehicles, whereas the entire petroleum industry is likely to face problems with it.The needs of potential buyers are competitive pricing with IC engine cars, easy to use technology, quick charging, and accessible charging infrastructure; car manufacturers will have to shift to producing electric vehicles if the demand shifts in that direction and would require capital investment and technical knowledge to do so and charging station owners most importantly need specific charging standards [21].

\subsection{Factors affecting the adoption of Electric Vehicles}

2.2.1. Charging Time: EV's require the consumer to shift from refueling at a gas station to plugging in their vehicle for recharge at a gas station. The consumer is accustomed to a 5minute refueling process at a gas station but is now required to plug in their vehicle at a charging station for approximately an hour for a full charge.

2.2.2. Charging Infrastructure: In 2018, India had about 650 charging stations compared to 456,000 charging points available in China [22]. The most fundamental requirement for the development of charging infrastructure is an expansion in the city's power grid as the recharging of EVs is accompanied by a considerable increase in the grid load. Another factor to be considered is the difference between recharging at peak load hours and non-peak hours.

2.2.3. Initial Cost: EVs generally cost considerably higher than a typical combustion engine vehicle. The high cost of lithium batteries takes the chunk in this overall cost. However, in the long term, the consumer can save a fortune on refueling cost as recharging a vehicle is way cheaper than petrol/diesel. Other ownership costs, such as vehicle maintenance and resale value, also add to consumer inhibitions in the purchase of EV's [23].

2.2.4. Distance Travelled: A significant deterrent to purchase of EV's is their comparatively shorter driving range, which is the shorter distance traveled on a full charge as compared to a gasoline vehicle's distance on a full tank.[24] This makes EV's inconvenient for traveling vast distances as the batteries will require repeated recharging. Thus, the typical driving pattern also plays a significant role in the purchasing decision process.

2.2.5. Supply Side constraints: All the big players of the automobile sector are slowly shifting their focus from ICEV's to EV's, and most of them are still in the design process of their respective EV models. EVs involves several new components and techniques of 
manufacturing that are currently being explored by Indian manufacturers. It will be a while before EVs occupy a significant share of the automobile market in Delhi.

\section{Research Methodology}

In this paper, AHP is coupled with TOPSIS to find the best attribute.

\subsection{Analytical Hierarchy Process (AHP)}

AHP approach is a multi-criterion decision-making method that can be done by segregating a particular problem into different levels of hierarchy. The method which was developed by Saaty [25] is used in this study. Here, the problem is divided into a hierarchy with the top and bottom level connotating objectives and attributes, respectively. Weights of the criterion (the middle level of the hierarchy) are calculated by constructing a pair-wise matrix with data being the relative importance of one criterion over the other, which is determined with the help of an expert's opinion. For data to be uniform, data is input on a 9-point scale, as shown in Table 1. The validation of the matrix is done by finding the largest Eigenvalue $\beta_{\max }$. Consistency Index (C) is calculated using Eq. (1) with $\mathrm{k}$ being the number of elements. With the help of the consistency index, Consistency Ratio (R) is evaluated with the help of Eq. (2) and Table 2. If $\mathrm{R}<=0.1$, then the matrix is acceptable.

Table 1. 9-point scale

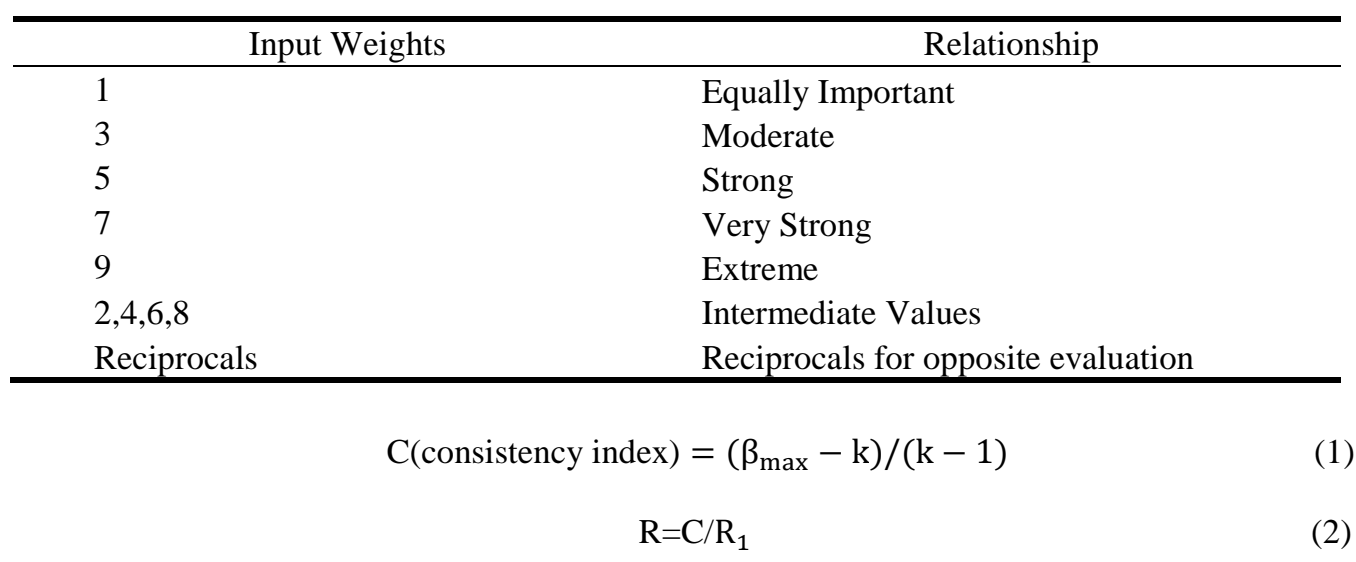

Table 2. Random Index Values

\begin{tabular}{ccccccccccc}
\hline Number of Attributes $(\mathrm{k})$ & 1 & 2 & 3 & 4 & 5 & 6 & 7 & 8 & 9 & 10 \\
\hline Random Index $\left(\mathrm{R}_{1}\right)$ & 0 & 0 & 0.52 & 0.39 & 1.11 & 1.25 & 1.35 & 1.4 & 1.45 & 1.49 \\
\hline
\end{tabular}

\subsection{Fuzzy TOPSIS Technique}


The Technique for Order of Preference by Similarity to Ideal Solution (TOPSIS) is for multicriterion decision problems. TOPSIS is derived from the concept of a compromise solution that is the nearest to a superseded optimum solution/attribute. The attributes are ranked on the basis of their closeness to the ideal solution. [26].

Customarily, crisp numbers are used to rank the attributes when TOPSIS is used. However, the vagueness of human judgment hinders the crisp numbers from capturing the appropriate/fitting situation [27]. One way to overcome this ambiguity is to involve Fuzzy Numbers, i.e., each linguistic term is assigned a number that can be used for further calculations. To select the best attribute, the following stepwise approach is employed [28].

Step 1: The most appropriate linguistic term is selected by experts for every attribute against every criterion - the proposed linguistic terms for this study, as shown in Table 3. The figure is used to assign the fuzzy number for each linguistic term.

Table 3. Fuzzy No for Linguistic Terms

\begin{tabular}{cc}
\hline Linguistic Term & Fuzzy Numbers \\
\hline Low & $(0.0,0.1,0.3)$ \\
Fairly Low & $(0.1,0.3,0.5)$ \\
Medium & $(0.3,0.5,0.7)$ \\
Fairly High & $(0.5,0.7,0.9)$ \\
High & $(0.7,0.9,1.0)$ \\
\hline
\end{tabular}

Step 2: The fuzzy decision matrix is obtained:

$$
\left[\begin{array}{cccccc}
\mathrm{W}_{11} & \mathrm{w}_{12} & \mathrm{w}_{13} & \cdots & \cdots & \mathrm{w}_{1 \mathrm{q}} \\
\mathrm{w}_{21} & \mathrm{w}_{22} & \mathrm{w}_{23} & \cdots & \cdots & \mathrm{w}_{2 \mathrm{q}} \\
\cdots & \cdots & \cdots & \cdots & \cdots & \cdots \\
\cdots & \cdots & \cdots & \cdots & \cdots & \cdots \\
\cdots & \cdots & \cdots & \cdots & \cdots & \cdots \\
w_{\mathrm{p} 1} & \mathrm{w}_{\mathrm{m} 2} & \mathrm{w}_{\mathrm{m} 3} & \cdots & \cdots & \mathrm{w}_{\mathrm{pq}}
\end{array}\right]
$$

Where $\mathrm{w}_{\mathrm{mn}}=\left(\mathrm{s}_{\mathrm{mn}}, \mathrm{t}_{\mathrm{mn}}, \mathrm{u}_{\mathrm{mn}}\right)$ represents the linguistic term, which has been converted to the fuzzy number using Table 3 , assigned to the $\mathrm{m}^{\text {th }}$ attribute in reference to the $\mathrm{n}^{\text {th }}$ factor. $\mathrm{m}=1,2, \ldots \ldots \ldots, \mathrm{p}$ are the attributes and $\mathrm{n}=1,2, \ldots \ldots \ldots, \mathrm{q}$ is the criterion.

Step 3: The fuzzy un-weighted matrix G is obtained as :

$$
\mathrm{G}=\left[\mathrm{g}_{\mathrm{mn}}\right]_{\mathrm{pXq}},\left[\mathrm{g}_{\mathrm{mn}}\right]=\left(\frac{\mathrm{s}_{\mathrm{mn}}}{\mathrm{u}_{\mathrm{n}}^{*}}, \frac{\mathrm{t}_{\mathrm{mn}}}{\mathrm{u}_{\mathrm{n}}^{*}}, \frac{\mathrm{u}_{\mathrm{mn}}}{\mathrm{u}_{\mathrm{n}}^{*}}\right)
$$

Where $u_{\mathrm{n}}^{*}=\max \mathrm{u}_{\mathrm{m}}$

Step 4: The Normalized matrix is obtained using the weights calculated in the AHP:

$$
\mathrm{B}=\left[\mathrm{b}_{\mathrm{mn}}\right]_{\mathrm{pq}} ; \mathrm{m}=1,2, \ldots \mathrm{p} ; \mathrm{n}=1,2, \ldots \mathrm{q}
$$

The value $b_{m n}$ is given by: 


$$
b_{m n}=g_{m n} \times t_{n}
$$

where $t_{n}(n \in q)$ represents $n^{\text {th }}$ criterion weight by performing the steps as mentioned in AHP.

Step 5: The ideal positive and the ideal negative solutions are obtained

$$
\begin{aligned}
& \mathrm{E}^{*}=\left\{\mathrm{a}_{1}^{*}, \ldots \ldots \ldots \mathrm{a}_{\mathrm{q}}^{*}\right\} \\
& \mathrm{E}^{-}=\left\{\mathrm{a}_{1}^{-}, \ldots \ldots \ldots . \mathrm{a}_{\mathrm{q}}^{-}\right\}
\end{aligned}
$$

For this study, the ideal solutions are taken from Agrawal et al. [29].

Step 6: Distances from ideal solutions are calculated using vector algebra, and their sum is calculated.

$$
\mathrm{I}_{\mathrm{n}}^{*}=\sum_{\mathrm{m}=1}^{\mathrm{p}} \mathrm{d}\left(\mathrm{a}_{\mathrm{mn}}-\mathrm{a}_{\mathrm{m}}^{*}\right) ; \mathrm{n}=1,2, \ldots \ldots \mathrm{q}
$$

Step 7: The proximity of each attribute to the negative ideal solution is calculated using the following expression.

$$
\mathrm{F}_{\mathrm{n}}=\frac{\mathrm{I}_{\mathrm{n}}^{-}}{\left(\mathrm{I}_{\mathrm{n}}^{*}+\mathrm{I}_{\mathrm{n}}^{-}\right)}, \mathrm{n}=1,2, \ldots \ldots \mathrm{q}
$$

Step 8: The attributes are ranked based on the proximity.

\section{Case Illustration:}

Relative Significance of Barriers can be modeled using the AHP-fuzzy TOPSIS Approach. The steps mentioned in the research methodology were followed to achieve a solution for the problem and explained below.

\subsection{Model the problem into a hierarchical structure:}

The problem is classified into the structure, as shown in Figure 1. The topmost shows the objective of the problem. The second most shows the criteria. The lowest hierarchy shows the sub-criterion with respect to the middle level. The hierarchy has been developed using expert opinions and literature reviews. 


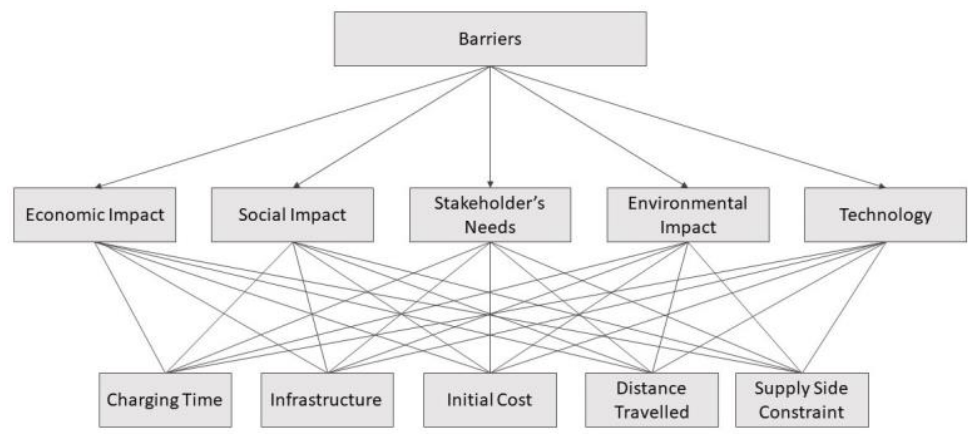

Figure 1: Hierarchal Structure

\subsection{Pair-wise comparison matrix:}

The pairwise comparison matrix is formed for the criteria with the help of a panel of experts. These experts rated these criteria against other criteria on the scale shown in Table 1. The steps mentioned in AHP were followed, and weights were calculated, as shown in Table 4.

Table 4 : Comparison Matrix

\begin{tabular}{ccccccc}
\hline Criteria & H1 & H2 & H3 & H4 & H5 & Weights \\
\hline Economic Impact (H1) & 1 & 7 & 2 & 5 & 3 & 0.415 \\
Social Impact (H2) & $1 / 7$ & 1 & $1 / 6$ & $1 / 3$ & $1 / 5$ & 0.040 \\
Stakeholder's needs (H3) & $1 / 2$ & 6 & 1 & 4 & 3 & 0.300 \\
Environmental Impact (H4) & $1 / 5$ & 3 & $1 / 4$ & 1 & $1 / 4$ & 0.075 \\
Technology (H5) & $1 / 3$ & 5 & $1 / 3$ & 4 & 1 & 0.173 \\
\hline
\end{tabular}

Economic Impact has the highest weight as the experts believed it to possess the most amount of significance. The matrix was validated with the calculation of Consistency Ratio (R), which came out to be less than 0.1 , as shown in Table 5 .

Table 5: Metrics of Comparison Matrix

\begin{tabular}{lr}
\hline$\beta_{\max }$ & 5.25 \\
$\mathrm{C}$ & 0.063 \\
$\mathrm{R}_{1}$ & 1.11 \\
$\mathrm{R}$ & 0.057 \\
\hline
\end{tabular}

\subsection{Determine the order of significance using TOPSIS approach:}

The experts rated the lowest level of the hierarchal structure, i.e., sub-criteria on a five-point scale. The opinion of the experts which consisted of linguistic terms, was converted into the fuzzy numbers with the help of Table 3. Steps mentioned in the research methodology concerning TOPSIS were carried out and the closeness coefficient was calculated as shown in Tables 6 and 7. 
Table 6: Decision Matrix

\begin{tabular}{clllll}
\hline & \multicolumn{1}{c}{ H1 } & \multicolumn{1}{c}{ H2 } & \multicolumn{1}{c}{ H3 } & H4 & H5 \\
\hline Charging Time & $\mathrm{M}(0.3,0.5,0.7)$ & $\mathrm{FL}(0.1,0.3,0.5)$ & $\mathrm{H}(0.7,0.9,1)$ & $\mathrm{FL}(0.1,0.3,0.5)$ & $\mathrm{FH}(0.5,0.7,0.9)$ \\
Infrastructure & $\mathrm{H}(0.7,0.9,1)$ & $\mathrm{M}(0.3,0.5,0.7)$ & $\mathrm{FH}(0.5,0.7,0.9)$ & $\mathrm{FH}(0.5,0.7,0.9)$ & $\mathrm{H}(0.7,0.9,1)$ \\
Initial Cost & $\mathrm{H}(0.7,0.9,1)$ & $\mathrm{FH}(0.5,0.7,0.9)$ & $\mathrm{H}(0.7,0.9,1)$ & $\mathrm{FL}(0.1,0.3,0.5)$ & $\mathrm{FH}(0.5,0.7,0.9)$ \\
Distance Travelled & $\mathrm{FH}(0.5,0.7,0.9)$ & $\mathrm{L}(0,0.1,0.3)$ & $\mathrm{FH}(0.5,0.7,0.9)$ & $\mathrm{M}(0.3,0.5,0.7)$ & $\mathrm{FH}(0.5,0.7,0.9)$ \\
Supply Side Constraint & $\mathrm{FH}(0.5,0.7,0.9)$ & $\mathrm{FL}(0.1,0.3,0.5)$ & $\mathrm{M}(0.3,0.5,0.7)$ & $\mathrm{L}(0,0.1,0.3)$ & $\mathrm{M}(0.3,0.5,0.7)$ \\
Weights & 0.415 & 0.04 & 0.3 & 0.08 & 0.173 \\
\hline
\end{tabular}

Higher the value of the closeness coefficient ,higher the rank. Accordingly, the barriers are ranked in the order of Infrastructure $(0.163)>$ Initial Cost $(0.162)>$ Distance Travelled $(0.138)>$ Charging Time (0.129) > Supply-Side Constraint (0.115) as shown in Table 7. It is evident from the results that considerable focus should be on upgrading Infrastructure and lowering the initial cost of Electric vehicles, i.e., to make it more affordable for Indian consumers.

Table 7: Distances to Ideal Solution and Rank

\begin{tabular}{ccccc}
\hline Barriers & $\mathbf{D}_{\mathbf{n}}^{*}$ & $\mathbf{D}_{\mathbf{n}}^{-}$ & $\mathbf{F}_{\mathbf{n}}$ & Ranking \\
\hline Charging Time & 4.376 & 0.651 & 0.129 & 4 \\
Infrastructure & 4.200 & 0.818 & 0.163 & 1 \\
Initial Cost & 4.205 & 0.813 & 0.162 & 2 \\
Distance Travelled & 4.333 & 0.693 & 0.138 & 3 \\
Supply Side Constraint & 4.453 & 0.579 & 0.115 & 5 \\
\hline
\end{tabular}

\section{Conclusion}

Several countries around the globe have successfully adopted the green mobility plan over a period. India faces numerous challenges in its attempt to replicate the same success. This paper has tried to elucidate the groundwork that needs to be carried out by all the major players (government, automobile industry, energy providers, etc.) for the fruitful introduction of the electric vehicle industry. The Fuzzy TOPSIS approach and expert's opinion prioritizes the setting up of charging infrastructure above all the other tasks mentioned in this paper. The interlinking of green renewable energy and charging infrastructure will also be a crucial part of this task. The other tasks also need to be worked upon simultaneously, and with time, India should be able to make strides in the development of the electric vehicle industry. Since this is a qualitative study, there is scope for further research to be done in this area by gathering data through various surveys as the existing data of electric vehicles in India is barely existent. 


\section{References}

[1] Climateactiontracker.org (2019). Pledges and Targets | Climate Action Tracker. Available at: https://climateactiontracker.org/countries/india/pledges-and-targets/.

[2] Granovskii, M., Dincer, I. and Rosen, M.A. (2006). Economic and environmental comparison of conventional, hybrid, electric and hydrogen fuel cell vehicles. Journal of Power Sources, 159(2), pp.1186-1193.

[3] Rezvani, Z., Jansson, J. and Bodin, J. (2015). Advances in consumer electric vehicle adoption research: A review and research agenda. Transportation Research Part D: Transport and Environment, 34, pp.122-136.

[4] Farhan Faisal (2017). An Analysis of Electric Vehicle Trends in Developed Nations: A Sustainable Solution for India. The Journal of Undergraduate Research at the University of Illinois at Chicago, 10(1). Available at: https://journals.uic.edu/ojs/index.php/JUR/article/view/8014/6400.

[5] PTI (2015). FAME-India scheme launched to offer sops on hybrid, e-vehicles. The Economic Times. Available at: https://economictimes.indiatimes.com/industry/fame-indiascheme-launched-to-offer-sops-on-hybrid-e-vehicles/articleshow/46853934.cms

[6] Krupa, J.S., Rizzo, D.M., Eppstein, M.J., Brad Lanute, D., Gaalema, D.E., Lakkaraju, K. and Warrender, C.E. (2014). Analysis of a consumer survey on plug-in hybrid electric vehicles. Transportation Research Part A: Policy and Practice, 64, pp.14-31.

[7] Lebeau, K., Lebeau, P., Mairesse, O., Macharis, C. and Mierlo, V. (2013). Consumer attitudes towards battery electric vehicles: A largescale survey. Int. J. Electric and Hybrid Vehicles, 5, pp.28-41.

[8] Ergon Energy. (2019). Benefits of Electric Cars. Available at: https://www.ergon.com.au/network/smarter-energy/electric-vehicles/benefits-of-electricvehicles

[9] Energy.gov. (2019). Reducing Pollution with Electric Vehicles. Available at: https://www.energy.gov/eere/electricvehicles/reducing-pollution-electric-vehicles.

[10] Powermin.nic.in. (2019). Power Sector at a Glance ALL INDIA /Government of India |Ministry of Power. Available at: https://powermin.nic.in/en/content/power-sector-glance-allindia.

[11] Wang, X., Gaustad, G., Babbitt, C.W., Bailey, C., Ganter, M.J. and Landi, B.J. (2014). Economic and environmental characterization of an evolving Li-ion battery waste stream. Journal of Environmental Management,135, pp.126-134. Available at: https://www.sciencedirect.com/science/article/pii/S030147971400036X\#kwrds0010

[12] Sierzchula, W., Bakker, S., Maat, K. and van Wee, B. (2014). The influence of financial incentives and other socio-economic factors on electric vehicle adoption. Energy Policy, 68, pp.183-194. Available https://www.sciencedirect.com/science/article/pii/S0301421514000822

[13] The Wire. (2018). India Set to Achieve 2 of 3 Paris Agreement Goals: Draft Government Report. Available at: https://thewire.in/environment/india-paris-climate-agreement-targets.

[14] Tech Desk (2019). India Budget 2019: New incentives for electric vehicles, tax benefits for buyers. The Indian Express. Available at: https://indianexpress.com/article/technology/tech-news-technology/budget-2019-newincentives-for-electric-vehicles-tax-benefits-for-buyers-5816645/

[15] Smiti (2019). India Formally Proposes Incentives for Electric Vehicles | CleanTechnica. Available at: https://cleantechnica.com/2019/06/27/india-formally-proposes-incentives-forelectric-vehicles/ 
[16] Liao, F., Molin, E. and van Wee, B. (2016). Consumer preferences for electric vehicles: a literature review. Transport Reviews, 37(3), pp.252-275.

[17] Vigo, J. (2018). Electric Vehicles and The Necessity of Cultural Change. Forbes. 17 Oct. Available at: https://www.forbes.com/sites/julianvigo/2018/10/17/electric-vehicles-and-thenecessity-of-cultural-change/\#1d11b1ecf23f

[18] Hugh (2018). Why are Electric Cars Important to Society? - The Benefits of Electric Vehicles. Get Green Now. Available at: https://get-green-now.com/why-are-electric-carsimportant/.

[19] Malmgren, I. (2016). Quantifying the Societal Benefits of Electric Vehicles. World Electric Vehicle Journal, 8(4), pp.996-1007.

[20] Talantsev, A. (2017). Who Gains and Who Loses in the Shift to Electric Vehicles: Impact Assessment through Multi-criteria Multi-stakeholder Analysis. Procedia Environmental Sciences, 37, pp.257-268.

[21] Bakker, S., Maat, K. and van Wee, B. (2014). Stakeholders interests, expectations, and strategies regarding the development and implementation of electric vehicles: The case of the Netherlands. Transportation Research Part A: Policy and Practice, [online] 66, pp.52-64. Available https://www.sciencedirect.com/science/article/pii/S096585641400113X?via\%3Dihub [22] Bloomberg.com. (2019). Bloomberg - Are you a robot? Available at: https://www.bloomberg.com/news/articles/2019-10-06/india-has-150-million-drivers-andonly-8-000-want-electric-cars

[23] Varga, B., Sagoian, A. and Mariasiu, F. (2019). Prediction of Electric Vehicle Range: A Comprehensive Review of Current Issues and Challenges. Energies, 12(5), p.946.

[24] Overcoming Barriers to Electric-Vehicle Deployment. (2013).Washington, D.C.: National Academies Press. Available at: https://www.nap.edu/catalog/18320/overcomingbarriers-to-electric-vehicle-deployment-interim-report

[25] Saaty, R.W. (1987). The analytic hierarchy process-what it is and how it is used. Mathematical Modelling, 9(3-5), pp.161-176. Available at: https://www.sciencedirect.com/science/article/pii/0270025587904738

[26] Multiple Attribute Decision Making (2019). Multiple Attribute Decision Making Methods and Applications A State-of-the-Art Survey | Ching-Lai Hwang | Springer. Springer.com. Available at: https://www.springer.com/gp/book/9783540105589

[27] Kim, Gyutai \& Park, Chan \& Yoon,K.Paul. (1997). Identifying investment opportunities for advanced manufacturing systems with comparative-integrated performance measurement. International Journal of Production Economics. 50. 23-33. 10.1016/S0925-5273(97)00014-5.

[28] Chen, C.-T. (2000). Extensions of the TOPSIS for group decision-making under fuzzy environment. Fuzzy Sets and Systems,114(1), pp.1-9. Available at: https://www.sciencedirect.com/science/article/pii/S0165011497003771

[29] Agrawal, S., Singh, R.K. and Murtaza, Q. (2016). Disposition decisions in reverse logistics by using AHP-fuzzy TOPSIS approach. Journal of Modelling in Management, 11(4), pp.932-948. 